\title{
Parent Perceptions and Attributions for Children's Math Achievement ${ }^{1}$
}

\author{
Doris K. Yee and Jacquelynne S. Eccles ${ }^{2}$ \\ University of Michigan
}

From junior high school on, girls report lower estimations of their math ability and express more negative attitudes about math than do boys, despite equivalent performance in grades. Parents show this same sex-typed bias. This paper examines the role that attributions may play in explaining these sex differences in parents' perceptions of their children's math ability. Mothers and fathers of 48 junior high school boys and girls of high, average, and low math ability completed questionnaires about their perceptions of their child's ability and effort in math, and their causal attributions for their child's successful and unsuccessful math performances. Parents' math-related perceptions and attributions varied with their child's level of math ability and gender. Parents credited daughters with more effort than sons, and sons with more talent than daughters for successful math performances. These attributional patterns predicted sex-linked variations in parents' ratings of their child's effort and talent. No sex of child effects emerged for failure attributions; instead, lack of effort was seen as the most important, and lack of ability as the least important, cause of unsuccessful math performances for both boys and girls. Implications of these attributions for parents' influence on children's developing self-concept of math ability, future expectancies, and subsequent achievement behaviors are discussed.

\footnotetext{
'This paper is based on a master's thesis by the first author. This research was funded by grants to Jacquelynne S. Eccles from the following agencies: the Foundation for Child Development, the National Institute of Mental Health, and the National Institute of Child Health and Development.

We wish to express our thanks to Linda Buford, Sandra Hamman, and Samuel D. Miller, who helped collect and code these data, and especially to the parents, students, and teachers in the Ann Arbor Public School district, whose cooperation made this project possible. ${ }^{2}$ To whom reprint requests should be addressed at Department of Psychology, University of Colorado, Box 345, Boulder, Colorado 80309.
} 
From junior high school on, girls express more negative attitudes toward math and rate their math ability lower than do boys even though objective indices suggest they are performing at comparable levels; furthermore, girls rate math as less important and less interesting than do boys (Eccles, Adler, \& Meece, 1984; Fennema, 1974; Fennema \& Sherman, 1977; Hilton \& Berglund, 1974). Females are also less likely than males to elect optimal advanced level math courses in both high school and colleges (Eccles et al., 1984; Ernest, 1976; Fennema \& Sherman, 1977). A wide variety of hypotheses have been generated and tested to explain these sex differences in math-related attitudes and behaviors. This paper focuses on one possible role that parents may play.

Several studies suggest that parents may contribute to these sex differences. For example, junior high school students rate their parents as the most influential people in their course enrollment decisions (Eccles et al., 1983); these students also rank parents second only to the usefulness of math in influencing their decision to take more math (Armstrong, 1980). Further, children's self-concept of ability and their confidence in math are more directly related to their parents' beliefs about their math aptitude and potential than to their own past achievement in math (Eccles-Parsons, Adler, \& Kaczala, 1982). Finally, parents, to a much greater extent than teachers, hold sexdifferentiated beliefs about their sons' and daughters' math achievement (Eccles-Parsons et al., 1982); in particular, while the parents in the EcclesParsons et al. (1982) study did not rate their daughters' math abilities significantly lower than that of their sons, they did think that math was more difficult for their daughters, that their daughters had to work harder in order to do well in math, and that enrollment in advanced level math courses was less important for daughters than for sons. These sex-differentiated perceptions existed even though boys and girls in this study had performed similarly on standardized math achievement tests and math grades. To the extent that parents convey the expectations inherent in these beliefs to their children, parents may help socialize the sex differences in students' attitudes toward mathematics. But two important questions need to be addressed: (1) Why do parents form such different perceptions of their sons' and daughters' math achievement when their children's performances are so similar? (2) What other variables affect parents' perceptions and attributions? These questions are the focus of this study.

Attribution theorists (e.g., Eccles et al., 1983; Frieze, Fisher, Hanusa, McHugh, \& Valle, 1978; Weiner, Nirenberg, \& Goldstein, 1976; Weiner, Frieze, Kukla, Reed, Rest, \& Rosenbaum, 1971) argue that people's causal expectations for successes and failure affect their self-concept of ability, future expectancies, and subsequent achievement behaviors. In particular, these theorists suggest that attributing success to stable factors such as ability should facilitate the acquisition of a positive self-concept to a greater extent than 
attributing success to unstable factors such as effort or luck. Conversely, attributing failure to stable, controllable factors such as insufficient effort should support a positive self-concept to a greater extent than attributing failure to stable, uncontrollable factors such as lack of ability. If parents make different attributions for their sons' and daughters' performance in math, then the inferential process suggested by attribution theory could account for the sex-differentiated parental beliefs outlined above. In particular, if parents are more likely to attribute their sons' success in math to ability and to attribute their daughters' success in math to effort, then they should conclude that math is easier for their sons than for their daughters even though their performances are equivalent.

One purpose of this study is to compare the causal attributions that parents make for their sons' and daughters' math performance. In line with the reasoning outlined above, we predict that parents of sons will attribute their child's math successes more to talent than parents of daughters, and that parents of daughters will attribute their child's math successes more to effort. Conversely, parents of sons will attribute their child's math failure more to lack of effort than parents of daughters, and parents of daughters will attribute their child's math failure more to lack of talent. In other words, parents may convey information regarding their beliefs about their children's abilities through the causal explanations they provide for their children's math successes and failures. Contrary to these predictions, however, Hess and his colleagues (Hess, Holloway, \& King, 1981; Holloway, Hess, \& King, 1981; King, Hess, \& Holloway, 1981) found that mothers attributed both sons' and daughters' academic successes to talent. Moreover, mothers thought that lack of effort was a more important explanation for poor performance than lack of talent, regardless of child sex, but believed lack of effort was a more important explanation for girls than for boys. By attributing poor performance to lack of effort, mothers may be saying that their child can do the work. But if mothers are also conveying the message that math is harder for girls than for boys, as suggested by Eccles-Parsons et al. (1982), then these two messages may end up undermining girls' math achievement as girls may then be less willing to exert the effort necessary to do as well on such a difficult task.

In addition to evidence that child sex is an important determinant of parents' math-related beliefs about their children, studies have also shown that the relationship between parents' attitudes toward math and children's attitudes toward math is dependent on the child's level of math ability (e.g., Wilhelm \& Brooks, 1980). Consequently, child's math ability level will be examined as another important determinant of parents' beliefs and expectations. Covington and Beery (1976) point out that the matching of performance expectations with a child's ability level is of prime importance in 
fostering a child's self-confidence and sense of competence. Thus we expect that parents of more able children will hold higher expectations and performance standards than parents of less able children. But we are particularly interested to see whether the interaction between child sex and math ability level affects parents' expectations and performance standards. For example, if parents entertain lower expectations for girls' than for boys' math performance, do they have much lower expectations for low-ability girls than for low-ability boys? Or conversely, do they have much higher expectations for high-ability boys than high-ability girls?

Establishing the relations between child's gender and ability level and parents' causal attributions is the first step in evaluating the attributional model outlined above. In brief, according to this model, parents develop different views of sons' and daughters' math ability because they make different causal attributions for their sons' and daughters' math performance. In particular, the attributional model predicts that, in comparison to daughters' math performance, parents will be more likely to attribute sons' math successes to talent and to attribute sons' failure to lack of effort. In contrast, in comparison to sons' math performance, parents should be more likely to attribute daughters' math successes to effort and to attribute daughters' math failures to lack of ability.

But the real test of the attributional model is to demonstrate the impact of these attributional biases on parents' perceptions of their sons' and daughters' math ability. To assess this relationship, we will correlate parents' causal attributions for their child's math success and failures with their ratings of their child's ability in mathematics and their child's effort in mathematics. Although the causal direction cannot be unequivocally inferred from these synchronous correlational patterns, significant relations do confirm the existence of the predicted relationship and thus point the way for further longitudinal investigations.

\section{METHOD}

\section{Sample}

This study is part of a large-scale, ongoing investigation of the impact of parental beliefs, values, and perceptions on children's developing task and self-perceptions. The data reported here were collected in 17 seventh-grade math classrooms of two junior high schools in a small Midwestern city. Both schools group students together according to their ability in math. School A groups students between classrooms so that within any one classroom students have approximately the same level of math ability. School B groups 
students within classrooms so that within any one classroom students have different levels of math ability, and are grouped for different instructional programs. Altogether 149 students ( 73 boys and 76 girls) were given a questionnaire. Of these 149 students, 48 students were sampled for intensive study of family influences. Twenty-four students from School A were matched on sex and math ability level (as assessed by the seventh grade Michigan Educational Assessment Program and fifth grade California Achievement Tests) with 24 students from School B, according to the sample plan displayed in Table I.

Parents of these 48 students completed a questionnaire at home about their beliefs, expectations, and causal attributions for their children's math achievement. For children of high and average math ability levels, both mothers and fathers participated. For children of low math ability levels, only mothers participated as several fathers could not be reached or refused to participate. Altogether 48 mothers and 32 fathers participated in this study.

Because School A and School B differed in their grouping practices, school effects were assessed, but none emerged. Henceforth, the school distinction is disregarded.

\section{Measures}

Parent Questionnaire. The parent questionnaire assessed parent perceptions, expectancies, and causal attributions for their child's math achievement. Parents were asked to rate the importance of various attributions in explaining their child's successful and unsuccessful math performances. For success attributions, parents rated the importance of talent, enjoyment, effort, task easiness, teacher help, parent help, and having good day. For failure attributions, parents rated the importance of lack of talent, lack of enjoyment, lack of effort, task difficulty, lack of teacher help, lack of parent help, and having a bad day. All causal attributions were rated on a scale from 1 (not at all important) to 7 (very important). In addition, parents were asked about their perceptions of their child's current overall school performance, current and future math performance, the amount of talent their child had in math, the amount of effort their child needed to expend in order to do

Table I. Sample Plan

\begin{tabular}{lccccc}
\hline & \multicolumn{2}{c}{ School A } & & \multicolumn{2}{c}{ School B } \\
\cline { 2 - 3 } \cline { 5 - 6 } Math ability level & Girls & Boys & & Girls & Boys \\
\hline High & 4 & 4 & & 4 & 4 \\
Average & 4 & 4 & & 4 & 4 \\
Low & 4 & 4 & & 4 & 4 \\
\hline
\end{tabular}


well in math, the extent to which their child's math performance matched his/her potential, and their minimum and maximum grade standards for their child's achievement. The first five items were rated on 7-point Likert-type scales anchored at the extremes with positive and negative descriptors. The item concerning the extent to which the child's math performance matched his/her potential was rated on a scale from 1 (very well) to 4 (not at all well). Responses to this item was reversed for all analyses reported here. Parents' minimum and maximum grade standards were coded on a scale from $1(F)$ to $14(A+)$. Parents were also asked how their child's current math performance compared to that of the previous year, how their child's talent and effort in math compared to his/her talent and effort in other subject areas, and how their minimum and maximum grade standards in math compared to such standards in other subject areas. These five items were rated on 3-point scales appropriately anchored at the extremes. Finally, parents were asked about their highest level of education, highest level math course taken and whether or not their current occupation involved math.

School Record Data. Information about the student's performance on the Michigan Educational Assessment Program (MEAP) and California Achievement Test (CAT), as well as math grades for both semesters of the 1981-1982 school year, were collected from each student's school file.

\section{RESULTS AND DISCUSSION}

\section{Parent's Background}

In comparison to mothers, fathers in our sample were better educated $\left[\chi^{2}(6, N=80)=22.72, p \leq .001\right]$, had taken higher level math courses $\left[\chi^{2}(4, N=80)=10.81, p \leq .05\right]$, and were slightly more likely to be employed in an occupation that involved math $\left[\chi^{2}(1, N=80)=3.02, p=\right.$ .08]. Only for mothers was there a significant relationship between parents' highest level math course and children's math ability level. More specifically, mothers of children with low math ability were less likely to have taken higher level math courses, as compared to mothers of children with high or average math ability $\left[\chi^{2}(8, N=48)=12.57, p \leq .05\right]$. When we eliminated these mothers of low math ability children, fathers were still better educated than mothers $\left[\chi^{2}(4, N=64)=13.49, p \leq .01\right]$, but fathers and mothers no longer differed on highest level math course taken $\left[\chi^{2}(4, N=64)=5.99\right.$, $p=.20$ ] nor on the likelihood of working in an occupation that involved math $\left[\chi^{2}(1, N=64)=1.56, p=.21\right]$. 


\section{Student Achievement Tests}

As a check on our manipulations, a 2 (child sex) $\times 3$ (math ability level) factorial analysis of variance (ANOVA) was performed on children's MEAP and CAT scores, and math grades for first and second semesters. Finding on MEAP scores indicated that high-ability students did not differ from average-ability students, but both groups differed from low-ability students $[F(2,37)=124.69, p<.0001, F(2,37)=34.79, p<.000$, for MEAP Objectives 1 and 2 respectively]. This finding was not surprising: as the MEAP objectives measure attainment of basic math skills, these results merely indicated that low math ability students in this sample had not mastered some essential math skills. Child ability level effects for CAT math scores and math grades were in the expected direction: high-ability students performed better than average-ability students, who in turn performed better than low-ability students $[F(1,41)=38.26, p<.0001 ; F(1,42)=7.15, p<.01$, for CAT total math and math grades respectively].

There were no child sex effects on either CAT math scores or math grades. On the MEAP math objectives girls did score higher than boys $[F(1$, $37)=11.98, p<.001 ; F(1,37)=8.11, p<.001$ for Objectives 1 and 2 respectively]; however, an inspection of the means indicated that this finding resulted from the dramatically low performance of low math ability boys in our sample. Boys and girls in high and average math ability groups did not differ on their performance on the MEAP math objectives $(p<.05)$.

\section{Interactions Between Child Sex and Math Ability Level}

There was an interaction between sex and math ability level for only two variables: fathers' relative minimum grade standards and fathers' attributions of success to task easiness. In general, fathers set a lower relative minimum grade standard for girls than boys [girls' mean $=1.63$, boys' mean $=2.31, F(1,28)=11.93, p \leq .01]$. However, an inspection of the means revealed that fathers' relative minimum standard was much lower for average ability level girls than boys [average ability girls' mean $=1.25$, average ability boys' mean $=2.38, F(1,28)=4.83, p \leq .05$ ], but there was no sex difference between high ability level girls and boys (high ability girls' mean $=2.00$, high ability boys' mean $=2.25$ ). Thus our prediction that parents would hold lower math achievement standards for their daughters than for their sons is partially confirmed. It is true for fathers only and only for students with average math ability. 
Fathers' ratings of the importance of the task easiness attribution also depended on child sex and math ability level $[F(1,27)=7.87, p \leq .01]$. Fathers rated task easiness as an equally important reason for the success of high ability level boys and girls (high-ability boys' mean $=2.63$, highability girls' mean $=3.00$ ), but they rated it as a much more important explanation for the success of average ability level boys than girls (averageability boys' mean $=5.13$, average-ability girls' mean $=2.43$ ). So consistent with our findings of lower minimum standards for average ability girls, fathers responded differently to sons' and daughters' of average ability.

Since there was no interaction between child sex and math ability level in any of the remaining analyses, the results for child sex and math ability level will henceforth be presented and discussed separately.

\section{Parents' Math-Related Beliefs and Child Math Ability Level}

A 2 (child sex) $\times 3$ (math ability level) factorial ANOVA was performed on mothers' and fathers' beliefs and causal explanations. The impact of child math ability is discussed first. Mothers' and fathers' data are discussed separately.

Mothers' Beliefs and Child Ability Level. Mothers' math-related perceptions of their child depended on the child's math ability level (see Table II). Mothers of more able children gave higher ratings to their child's general school performance and current math performance. These mothers also thought their child would do better in future math courses and held a higher maximum grade standard. Further, they reported that their child was more talented in math, more talented in math relative to other subjects, and closer to reaching his/her potential in math. Finally, trends suggested that these mothers thought their child required less effort to do well in math and less effort to do well in math relative to other subjects.

Mothers' Causal Attributions and Child Ability Level. Mothers' causal attributions also depended on the child's math ability level. Mothers of more able children rated talent as a more important reason for their child's math successes while mothers of less able children rated effort as a more important explanation. This finding is consistent with notions that performance is a joint function of ability and effort, and that ability and effort are inversely or compensatorily related to one another in determining outcomes (Covington, 1984; Nicholls, 1984). Mothers of less able children also rated parent help as more important cause of child math success than did mothers of more able children.

Comparing the relative importance of various success attributions also yielded interesting differences. Talent and enjoyment, both stable attributions, were rated as the two most important causes of success for high-ability 
Table II. Impact of Child's Math Ability Level on Parents' Achievement-Related Perceptions and Expectations $s^{a, b}$

\begin{tabular}{|c|c|c|c|c|c|c|c|}
\hline \multirow[b]{2}{*}{ Variable } & \multicolumn{4}{|c|}{ Mothers $^{c}$} & \multicolumn{3}{|c|}{ Fathers $^{d}$} \\
\hline & High & Average & Low & $F$ ratio & High & Average & $F$ ratio \\
\hline General school performance & 6.31 & 5.38 & 4.19 & $16.75^{i}$ & 5.94 & 5.31 & $3.93^{f}$ \\
\hline Current math performance & 5.94 & 4.75 & 3.69 & $11.13^{i}$ & 5.94 & 4.88 & $12.57^{h}$ \\
\hline Future math performance & 6.25 & 5.31 & 4.44 & $8.15^{h}$ & 6.06 & 5.19 & $1.89^{\circ}$ \\
\hline Maximum standard & 13.13 & 12.63 & 11.44 & $12.50^{i}$ & 13.06 & 12.81 & $2.95^{e}$ \\
\hline Minimum standard & 9.63 & 9.19 & 8.69 & - & 9.75 & 9.00 & - \\
\hline Relative minimum standard & 2.06 & 1.94 & 1.88 & - & 2.13 & 1.81 & - \\
\hline Required effort & 3.81 & 4.50 & 4.56 & - & 3.75 & 4.88 & $4.93^{f}$ \\
\hline Relative effort & 1.81 & 2.19 & 2.25 & $2.47^{\circ}$ & 1.94 & 2.13 & - \\
\hline Talent & 5.88 & 4.81 & 4.13 & $12.40^{i}$ & 5.69 & 5.00 & $5.68^{f}$ \\
\hline Relative talent & 2.38 & 1.88 & 1.88 & $3.73^{f}$ & 2.06 & 2.06 & - \\
\hline Doing as well as possible & 3.31 & 2.69 & 2.38 & $5.95^{8}$ & 3.31 & 3.00 & _- \\
\hline \multicolumn{8}{|l|}{ Success attributions } \\
\hline Talent & 5.63 & 4.50 & 3.69 & $7.77^{h}$ & 5.63 & 4.81 & $3.83^{\circ}$ \\
\hline Enjoyment & 5.56 & 4.88 & 4.44 & - & 4.88 & 4.44 & - \\
\hline Effort & 4.63 & 5.75 & 5.69 & $3.18^{f}$ & 5.19 & 5.19 & - \\
\hline Task easiness & 3.19 & 3.13 & 3.88 & - & 2.81 & 3.87 & $3.10^{\circ}$ \\
\hline Teacher help & 4.75 & 5.13 & 5.56 & - & 4.25 & 5.25 & $3.41^{\circ}$ \\
\hline Parent help & 2.13 & 2.06 & 4.00 & $7.08^{8}$ & 1.75 & 2.63 & - \\
\hline Good day & 2.94 & 3.75 & 4.13 & - & 2.67 & 3.19 & - \\
\hline \multicolumn{8}{|l|}{ Failure attributions } \\
\hline Lack of talent & 2.00 & 2.88 & 3.50 & $3.00^{\circ}$ & 1.53 & 2.38 & $4.53^{f}$ \\
\hline Lack of enjoyment & 2.60 & 3.31 & 3.94 & - & 2.40 & 3.50 & $2.97^{\circ}$ \\
\hline Lack of effort & 4.93 & 5.31 & 5.50 & - & 5.67 & 4.94 & - \\
\hline Task difficulty & 3.86 & 4.13 & 4.53 & - & 3.13 & 4.31 & $3.67^{\circ}$ \\
\hline Lack of teacher help & 2.80 & 3.50 & 4.69 & $2.84^{e}$ & 2.79 & 3.25 & - \\
\hline Lack of parent help & 2.73 & 2.56 & 4.94 & $6.92^{8}$ & 2.28 & 2.50 & - \\
\hline Bad day & 3.20 & 3.06 & 3.80 & - & 3.07 & 2.94 & - \\
\hline
\end{tabular}

${ }^{a} F$ ratios are derived from two-way ANOVAs, with child math ability level and child sex as independent factors.

${ }^{b}$ Items regarding maximum and minimum grade standards are coded from $1(F)$ to $14(A+)$. Items about relative minimum standard, relative effort, and relative talent are rated on 3-point scales. The item about performance matching potential is rated on a 4-point scale. All other items are rated on 7-point scales.

${ }^{c} N s$ range from 46 to 48 .

${ }^{d} N s$ range from 30 to 32 .

${ }^{e} p \leq .10$.

$f_{p} \leq .05$.

${ }_{p}{ }_{p} \leq .01$.

${ }^{n} p \leq .001$.

$i_{p} \leq .0001$.

students; effort was rated fourth. In contrast, effort and teacher help, both unstable attributions, were rated as the most important causes of success for both average- and low-ability students. For average-ability students, talent was rated fourth; for low-ability students, talent was rated the least important cause of math success. These patterns present clear evidence of a compensatory relationship between effort and talent: even though the ratings for 
effort and talent are assessed independently of each other, the causal importance of effort increases as the causal importance of talent declines.

As for math failures, only lack of parent help yielded a significant effect for child math ability level. Mothers of less able children rated lack of parent help as a more important cause of failure than did mothers of more able children. This result, coupled with the comparable effect for math success, suggests that mothers of less able children think they are more responsible for their children's academic performances in math than other mothers. Whether such a pattern promotes feelings of guilt or hopefulness probably depends on these mothers' confidence in their ability to in fact help their low-performing child improve.

Comparing the relative importance of the various failure attributions, we find that all mothers rated lack of effort, an unstable attribution, as the most important explanation. Mothers of high- and average-ability children rated task difficulty as the next most important explanation, while mothers of low-ability children rated lack of parent help as next most important. All mothers, even those of low-ability children, considered lack of talent the least important explanation for math failures.

Fathers' Beliefs and Child Ability Level. Fathers' opinions about their child also depended on the child's math ability level (Table II) and followed a pattern similar to mothers' opinions. Fathers of more able children gave higher ratings to their child's general school performance, current math performance, as well as future math performance. These fathers also reported that their child was more talented in math and required less effort to do well in math. Unlike mothers, however, fathers of both high- and average-ability children believed their child was reaching his/her potential in math, perhaps because fathers of average-ability children believed their child was exerting more effort to compensate for their lower level of talent.

Fathers' Causal Attributions and Child Ability Level. There were no significant effects of child math ability on fathers' success attributions. In part this may reflect the attenuated ability range among this sample of fathers. Despite the lack of differences, however, the relative importance of the various attributions for each ability group matches the relative ordering of mothers' attributions. Fathers of high-ability children rated talent as the most important reason for math success, followed by effort and enjoyment. Fathers of average-ability children rated teacher help and effort as the most important reasons, followed by talent.

As for math failures, only lack of talent yielded a significant effect for child math ability level. Fathers rated lack of talent as a more important reason for math failures of the less able child. However, when we compare the relative importance of the various failure attributions, fathers, like mothers, considered lack of talent as the least important reason for math failure, and 
lack of effort and task difficulty as most important reasons. This pattern of attributions was true for fathers of high- or average-ability level children.

\section{Discussion of Ability Level Effects}

Parents were clearly sensitive to their child's math capabilities. Parents' perceptions, expectations, and performance standards were commensurate with their child's math ability level. Consistent with math achievement test scores and grades, they thought the more able child was currently doing better in math, and compared to the less able child, they thought this child would do better in future math courses. They held higher performance standards for the more able child. Mothers credited more able children with talent and less able children with effort. Mothers rated talent as a more important reason for the math success of the more able child, whereas effort and parent help were rated as the primary causes of success for the less able child. Mothers also rated lack of parental help as a very important reason for the math failures of the less able child.

In interpreting the causal attributions, it is important to consider the importance of each attribution relative to all the other attributions. Regarding success attributions in the high- and average-ability groups, both mothers and fathers gave greater importance to internal attributions (ability and effort) than to external ones (task easiness and having a good day). Yet parents rated talent as the most important reason for the child with high math ability while effort was the most important reason for the child with average math ability. For low-ability children, mothers rated unstable attributes such as effort and teacher help as more important than stable attributes such as ability.

Regarding failure attributions, lack of effort was rated as the most important reason for all ability levels. Task difficulty was second most important for all groups expect the low-ability students. Finally, lack of talent was rated as the least or almost least important reason for failure outcomes of all ability levels. Thus, although parents tended to endorse lack of talent as a more important explanation for math failures of less able children, lack of talent was the least preferred of all the failure attributions.

\section{Parents' Math-Related Beliefs and Child Sex}

Mothers' Beliefs and Child Sex. As predicted, in comparison to mothers of boys, mothers of girls thought that their child was less talented in math 
Table III. Impact of Child Sex on Parents' Achievement-Related Perceptions and Ex-

\begin{tabular}{|c|c|c|c|c|c|c|}
\hline \multirow[b]{2}{*}{ Variable } & \multicolumn{3}{|c|}{ Mothers $^{c}$} & \multicolumn{3}{|c|}{ Fathers $^{d}$} \\
\hline & Girls & Boys & $F$ ratio & Girls & Boys & $F$ ratio \\
\hline General school performance & 5.50 & 5.08 & - & 6.06 & 5.19 & $7.71^{8}$ \\
\hline Current math performance & 4.83 & 4.75 & - & 5.69 & 5.13 & $3.52^{e}$ \\
\hline Future math performance & 5.33 & 5.33 & - & 5.81 & 5.44 & - \\
\hline Maximum standard & 12.25 & 12.54 & - & 13.06 & 12.81 & $2.95^{e}$ \\
\hline Minimum standard & 9.04 & 9.29 & - & 9.19 & 9.56 & - \\
\hline Relative minimum standard & 1.96 & 1.96 & - & 1.63 & 2.31 & $11.93^{8}$ \\
\hline Required effort & 4.83 & 3.75 & $6.52^{\mathrm{g}}$ & 4.25 & 4.38 & - \\
\hline Relative effort & 2.38 & 1.79 & $11.25^{8}$ & 2.19 & 1.88 & - \\
\hline Talent & 4.71 & 5.17 & - & 5.31 & 5.38 & - \\
\hline Relative talent & 1.83 & 2.25 & $5.83^{f}$ & 2.00 & 2.13 & - \\
\hline Doing as well as possible & 2.83 & 2.75 & - & 3.47 & 2.88 & $5.81^{f}$ \\
\hline \multicolumn{7}{|l|}{ Success attributions } \\
\hline Talent & 4.21 & 5.00 & $3.86^{f}$ & 5.19 & 5.25 & - \\
\hline Enjoyment & 4.63 & 5.29 & - & 4.88 & 4.44 & - \\
\hline Effort & 5.75 & 4.96 & $3.74^{f}$ & 5.56 & 4.81 & - \\
\hline Task easiness & 3.63 & 3.17 & - & 2.73 & 3.88 & $4.50^{f}$ \\
\hline Teacher help & 4.88 & 5.42 & - & 5.06 & 4.44 & - \\
\hline Parent help & 2.67 & 2.79 & - & 2.00 & 2.38 & - \\
\hline Good day & 3.71 & 3.50 & - & 2.57 & 3.25 & - \\
\hline \multicolumn{7}{|l|}{ Failure attributions } \\
\hline Lack of talent & 3.09 & 2.54 & - & 1.60 & 2.31 & $3.30^{e}$ \\
\hline Lack of enjoyment & 3.57 & 3.04 & - & 3.40 & 2.56 & - \\
\hline Lack of effort & 5.43 & 5.08 & - & 5.33 & 5.25 & - \\
\hline Task difficulty & 4.65 & 3.70 & $3.47^{e}$ & 3.73 & 3.75 & - \\
\hline Lack of teacher help & 3.52 & 3.83 & - & 3.14 & 2.94 & - \\
\hline Lack of parent help & 3.48 & 3.38 & - & 2.14 & 2.63 & - \\
\hline Bad day & 3.30 & 3.39 & - & 2.86 & 3.13 & - \\
\hline
\end{tabular}

${ }^{a} F$ ratios are derived from two-way ANOVAs, with child math ability level and child sex as independent factors.

${ }^{b}$ Items regarding maximum and minimum grade standards are coded from $1(F)$ to 14 $(A+)$. Items about relative minimum standard, relative effort, and relative talent are rated on 3-point scales. The item about performance matching potential is rated on a 4-point scale, and reversed. All other items are rated on 7-point scales.

${ }^{c} N$ s range from 46 to 48 .

${ }^{d} N$ s range from 30 to 32 .

${ }^{e} p \leq .10$.

$f_{p} \leq .05$.

${ }^{8} p \leq .01$.

in comparison to other subjects, that their daughter had to try harder in math in the absolute and in comparison to other subjects (see Table III).

Mothers' Causal Attributions and Child Sex. Sex effects on mothers' causal attributions for math success also confirmed our predictions. Mothers of sons gave math talent a higher rating of causal importance for their child's math success than did mothers of daughters. In contrast, mothers of daughters gave effort a higher rating of causal importance for their child's math success than did mothers of sons. In addition, mothers of daughters rated 
effort, by a substantial margin, as the most important reason for their child's math success; talent came in a distant fourth after teacher help and employment. In contrast, mothers of sons rated teacher help and enjoyment as the two most important explanations, while both effort and talent came in a close third in terms of relative importance. When we eliminated mothers of low math ability children to make the mother sample parallel to the father sample, mothers of high- and average-ability sons considered talent and enjoyment as the most important reasons for their child's math success.

There were no significant sex efforts for mothers' causal attributions for their child's math failure. However, mothers of both boys and girls rated lack of effort as the most important reasons and lack of talent as the least important. This was true even when we eliminated mothers of low math ability children.

Fathers' Beliefs and Child Sex. Fathers' beliefs were also related to child sex (Table III), but in a somewhat different manner than mothers' beliefs. Compared to fathers of boys, fathers of girls believed their child was doing better in school. However, compared to fathers of daughters, fathers of sons expected a higher minimum grade standard for math performance and believed their child was not doing as well as possible. These differences suggest that fathers of sons were more disappointed with the academic progress of their child than were fathers of daughters.

Fathers' Causal Attributions and Child Sex. Fathers' ability and effort explanations for sons' and daughters' math successes followed the same pattern as did those of mothers, although the sex differences were not significant. Fathers of sons also thought task easiness was a more important explanation for their child's math success than did fathers of daughters. Again, this finding suggests that fathers may be more demanding of their sons' academic performance than of their daughters'. Like mothers, fathers tended to rate ability as a relatively more important explanation for sons' math successes, but effort as a relatively more important cause of daughters' math successes. In addition, as was the case for mothers, child's sex did not influence fathers' causal attributions for math failure. Lack of effort was rated as the most important reason, by a large margin, for both boys' and girls' math failures. Task difficulty and lack of teacher help were also considered among the most important explanations, while lack of talent was rated the least important.

Relations Between Attributions and Parent Perceptions. Zero-order correlations were calculated to assess the possible impact of mothers' sexbiased attributions on their percpetions of their sons and daughters. The attributions of success to both talent and effort correlated with mothers' estimates of children's math effort and math talent in the predicted direction (see Table IV). Attributing their child's math successes to talent related positively to mothers' estimates of their child's math talent. But perhaps more 
Table IV. Mothers' Success Attributions and Math-Related Perceptions ${ }^{a}$

\begin{tabular}{lrr}
\hline & \multicolumn{2}{c}{ Success attributions } \\
\cline { 2 - 3 } Math-related perceptions & Talent & Effort \\
\hline Required effort & $-.34^{b}$ & $.30^{b}$ \\
Relative effort & $-.54^{e}$ & $.52^{d}$ \\
Talent & $.67^{e}$ & $-.43^{c}$ \\
Relative talent & $.42^{e}$ & $-.50^{d}$ \\
\hline
\end{tabular}

${ }^{a}$ Relative effort and relative talent items are rated on 3-point scales. All other items are rated on 7-point scales.

${ }^{b} p \leq .05$.

$c p \leq .01$.

$d p \leq .001$

$e^{e} \leq .0001$.

importantly, attributing their child's math success to effort related negatively to a mothers' estimates of their child's talent.

\section{Discussion of Child Sex Effects}

Although boys and girls were doing equally well according to achievement test scores and math grades, mothers and fathers held different beliefs about sons' and daughters' math ability and effort, different expectations and performance standards, and different causal explanations for achievement outcomes. A consistent pattern emerged in parents' ability and effort assessments, and in their causal attributions for success. Although objective indices indicated that girls and boys were doing equally well in math, both mothers and fathers credited boys with talent and girls with effort. This difference was even more marked when we compared the relative importance of effort and talent as causal explanations for children's math success. With the exception of teacher help, both mothers and fathers endorsed internal factors (ability, effort, enjoyment) as more important than external ones (task easiness and having a good day). According to attribution theory, attributing success to internal factors enhances one's sense of control over future achievement outcomes.

However, both mothers and fathers rated ability as the most important reason for boys and effort as the most important reason for girls. Talent is a stable attribute while effort is an unstable one. And while both are seen as important reasons for math success, that parents rate their relative importance differently for boys and girls may contribute to the inferences they draw regarding their children's math talent and indirectly to the inferences that their children develop regarding their own math talent, their fu- 
ture prospects for success, and the amount of effort it will take to continue succeeding at math. Correlational analyses of mothers' attributions and ratings of their child's math talent support this suggestion. Parents may thus inadvertently encourage boys to develop higher and more stable estimates of their math ability and greater confidence in their continued future success. In contrast, by placing greater focus on the relative importance of effort as a cause of their daughters' math successes, parents may inadvertently undermine both their own and their daughters' estimates of the daughters' math talent, and thus raise possible doubts about continued success in an activity that they presume gets increasingly difficult (Eccles et al., 1983). In addition, since success in math is dependent upon both talent and effort, underestimating one's talent may lead one to overestimate the amount of effort needed for success, thereby raising the cost of continued participation in math-related courses (see Eccles et al., 1984, for a full discussion of this hypothesis).

Contrary to predictions from attribution theory, parents saw math failures as primarily the result of lack of effort or task difficulty; lack of talent was considered the least important explanation. This was true even when we removed mothers of low math ability children. As an extension of attribution theory, we might predict that parents would attribute boys' failures to lack of effort but girls' failures to lack of ability. As an attribution to lack of ability is more debilitating to one's self-esteem and self-confidence, we might then argue that parents thus influence girls to develop lower estimations of their math ability. However, our data show that parents most prefer lack of effort as an explanation for math failures of both boys and girls. Thus parents seem to be conveying the message that successful math performance is within the control of both boys and girls: by exerting more effort, both boys and girls can do better in math. To the extent that parents' attributions impact differentially on girls and boys, it is their attributions for success that are likely mediators, not their attributions for failure.

\section{SUMMARY}

The interaction between child's sex and math ability level seemed to have almost no impact on parents' math-related perceptions and expectations. Exceptions were fathers' relative minimum grade standard and fathers' success attributions to task easiness. Fathers held a lower grade standard for less able daughters than for less able sons. Fathers rated task easiness as a much more important explanation for the math successes of less able boys than less able girls, but equally important for the math successes of more able girls and more able boys. 
Parents' perceptions and expectations were commensurate with their child's level of math ability. Consistent with achievement test scores and math grades, mothers and fathers thought that the more able child was doing better in math, and would continue to do better in future math courses. They expected higher minimum and maximum grade standards from this child, and there was a trend that parents believed it was more important for this child to do well in math. They thought math successes of the more able child were due to talent, while those of the less able child were due to effort. But both parents thought that lack of effort was the most important reason for children's failures regardless of their level of math ability.

Mothers' attributions for math successes differed for boys and girls. Mothers credited their sons' successes more to talent than their daughters' and their daughters' successes more to effort than their sons'. Fathers' ability attributions did not differ for boys and girls, but fathers' effort attributions followed a pattern similar to mothers'. As talent is a stable attribution while effort is an unstable one, parents may be communicating confidence about their sons' future math success while conveying doubts about that of their daughters. Negative correlations between mothers' effort attributions and their estimates of their child's math talent lend support to this suggestion. Mothers who attributed their child's math success to effort also held lower estimates of their child's math talent. Parents who maintain sexdifferentiated ability and effort attributions will fail to offer girls an alternative interpretation for their math successes when in fact they are performing equally as well as boys. Contrary to expectations from attribution theory, there were no sex differences in parents' ratings of the importance of various attributions for math failures.

Parents generally preferred internal to external success attributions: both mothers and fathers rated teacher help, effort, talent, and enjoyment as the most important reasons for child math success. This finding suggests that parents believe children are responsible for their math successes. The exception is teacher help, which also ranked very highly among parents. Although attributing success to teacher help seems to be invoking an external factor, it may be that having a good teachers is associated with an improvement in internal factors such as talent and effort - that is, a good teacher brings out latent talent in math or motivates effortful performance in math. Generally, parents most preferrred talent as an explanation for boys' successes and effort as an explanation for girls' successes.

In short, these data provide evidence for the classic attribution pattern in parents' assessments of the importance of ability and effort to children's math success. For math failures, however, both mothers and fathers most preferred lack of effort and task difficulty, and least preferred lack of talent, as important explanations. These findings suggest that parents' attri- 
butions for success are more likely mediators of sex differences in their children's math performance, and not their attributions for failure.

\section{REFERENCES}

Armstrong, J. M. Achievement and participation of women in mathematics: An overview. (Report No. 10-MA-00). Denver, CO; National Assessment of Educational Progress, 1980. (ERIC Document Reproduction Service No. ED 184 878).

Covington, M. V. The motive for self-worth. In R. E. Ames \& C. Ames (Eds.), Research on motivation in education, vol. I, student motivation. Orlando, FL: Academic Press, 1984.

Covington, M. V., \& Beery, R. G. Self-worth and school learning. New York: Holt, Rinehart and Winston, 1976.

Eccles, J. E., Adler, T. F., \& Meece, J. L. Sex differences in achievement: A test of alternate theories. Journal of Personality and Social Psychology, 1984, 46, 26-43.

Eccles, J. E., Adler, T. F., Futterman, R., Goff, S. B., Kaczala, C. K., Meece, J. L., \& Midgley, C. Expectancies, values, and academic behaviors. In J. T. Spence (Ed.), Perspectives on achievement and achievement motivation. San Francisco: Freeman, 1983.

Eccles-Parsons, J. S., Adler, T. F., \& Kaczla, C. M. Socialization of achievement attitudes and beliefs: Parental influences. Child Development, 1982, 53, 310-321.

Ernest, J. Mathematics and sex. Santa Barbara, CA: University of California Press, 1976.

Fennema, E. Mathematics learning and the sexes: A review. Journal for Research in Mathematics Education, 1974, 126-139.

Fennema, E., \& Sherman, J. Sex-related differences in mathematics achievement, spatial visualization, and affective factors. American Educational Research Journal, 1977, 14, 51-71.

Frieze, I. H., Fisher, J., Hanusa, B., McHugh, M., \& Valle, V. Attributing the causes of success and failure: Internal and external barriers to achievement in women. In J. Sherman \& F. Denmark (Eds.), Psychology of women: Future directions of research. New York: Psychological Dimensions, 1978.

Hess, R. D., Holloway, S., \& King, D. R. Causal explanations for low and high performance in school: Some contrasts between parents and children. Paper presented at the biennial meeting of the Society for Research in Child Development, Boston, 1981.

Hilton, T. L., \& Berglund, G. W. Sex differences in mathematics achievement: A longitudinal study. Journal of Educational Research, 1974, 67, 231-237.

Holloway, S., Hess, R. D., \& King, D. R. Mothers' and children's explanations for school performance: Relation to academic achievement. Paper presented at annual meeting of the American Educational Research Association, Los Angeles, 1981.

King, D., Hess, R., \& Holloway, S. A study of mothers and children's causal attributions about children's performance in school subjects. Paper presented at the annual meeting of the American Educational Research Association, Los Angeles, 1981.

Nicholls, J. G. Conceptions of ability and achievement motivation. In R. E. Ames \& C. Ames (Eds.), Research on motivation in education, vol. 1, student motivation. Orlando, FL: Academic Press, 1984.

Weiner, B., Nirenberg, R., \& Goldstein, M. (1976). Social learning (locus of control) versus attributional (causal stability) interpretation of expectancy of success. Journal of Personality, 1976, 44, 52-68.

Weiner, B., Frieze, I., Kukla, A., Reed, L., Rest, S., \& Rosenbaum, R. Perceiving the causes of success and failure. In E. E. Jones (Ed.), Attribution: Perceiving the causes of behavior. New York: General Learning Press, 1971.

Wilhelm, S., \& Brooks, D. M. The relationship between pupil attitudes toward math and parental attitudes toward math. Educational Research Quarterly, 1980, 5, 8-16. 